\title{
PENETAPAN KADAR ASAM BENZOAT DALAM BEBERAPA MERK DAGANG MINUMAN RINGAN SECARA SPEKTROFOTOMETRI ULTRAVIOLET
}

\section{DETERMINATION OF BENZOIC ACID LEVELS IN SOME BRAND NAME OF SOFT DRINKS BY ULTRAVIOLET SPECTROPHOTOMETRY}

\author{
Wahyu Irna Wati, Any Guntarti \\ Fakultas Farmasi Universitas Ahmad Dahlan \\ Jl. Prof. Dr. Supomo Yogyakarta, Telp. (0274) 379418
}

\section{Abstrak}

Asam benzoat merupakan salah satu pengawet sintetik yang bekerja efektif pada pH 2,5-4,0 sehingga banyak digunakan pada makanan atau minuman yang bersifat asam. Penelitian ini bertujuan untuk mengetahui kadar asam benzoat dalam berbagai merk dagang minuman ringan, kesesuaiannya dengan Permenkes RI No.722/ Menkes/Per/IX/88 tentang bahan tambahan pangan, dan apakah terdapat perbedaan kadar asam benzoat dalam minuman ringan dengan merk yang berbeda. Penetapan kadar asam benzoat dilakukan secara spektrofotometri ultraviolet, yang sebelumnya asam benzoat dari sampel diekstraksi dengan pelarut kloroform. Secara kualitatif ditemukan bahwa semua sampel mengandung asam benzoat. Secara kuantitatif, kadar asam benzoat dalam sampel Merk A 227,73 mg/kg bahan; Merk B 182,38 mg/kg bahan; Merk C 259,52 mg/kg bahan; Merk D 325,01 mg/kg bahan; Merk E 357,33 mg/kg bahan. Dari hasil penelitian tersebut dapat diketahui bahwa terdapat perbedaan kadar asam benzoat dalam minuman ringan dengan merk yang berbeda. Penggunaan asam benzoat dalam minuman ringan sesuai dengan Permenkes RI No.722/ Menkes/Per/IX/88, tidak melebihi batasan maksimal yang ditentukan yaitu sebesar 600 $m g / k g$ bahan.

Kata Kunci : Minuman Ringan, Spektrofotometri Ultraviolet, Asam Benzoat 


\section{Abstract}

Benzoic acid is one of the synthetic preservatives, work effectively at $\mathrm{pH} 2.5$ to 4.0, therefore it is widely used in acidic food or drink. This study aims to determine benzoic acid content in some soft drink products, their conformity with Permenkes RI No. $722 /$ Menkes/Per/IX/88 on food additives, and to find out if there were any variance of benzoid acid content in a different kinds of soft drink products.

Determination of benzoid acid levels was performed by ultraviolet spectrophotometry following solvent extraction of the benzoid acid with chloroform. Qualitatively, it was found that all of the sample contained benzoid acid. Quantitatively, the amount of benzoid acid in sample A was $227,73 \mathrm{mg} / \mathrm{kg}$ of materials; sample $B$ was $182,38 \mathrm{mg} / \mathrm{kg}$ of materials; sampel C was $259,52 \mathrm{mg} / \mathrm{kg}$ of materials; sample D was $325,01 \mathrm{mg} / \mathrm{kg}$ of materials; sample E was $357,33 \mathrm{mg} / \mathrm{kg}$ of material. The result indicated that there were variance of benzoid acid content in different soft drink products. The use of benzoic acid in soft drinks was lower compaired to that of Permenkes RI No.722/Menkes/Per/IX/88 (600 mg/kg of materials).

Keywords : Soft Drinks, Ultraviolet Spectrophotometry, Benzoic Acid

\section{PENDAHULUAN}

Seiring dengan pertumbuhan industri makanan dan minuman di Indonesia, telah terjadi peningkatan produksi minuman ringan yang beredar di masyarakat. Pada minuman ringan sering ditambahkan bahan tambahan makanan, salah satunya adalah pengawet sintetik. Penggunaan bahan pengawet sintetik tersebut harus diperhatikan kadarnya karena apabila konsumsinya berlebih dapat membahayakan kesehatan (Jacobson, 2000).

Salah satu bahan pengawet yang banyak digunakan adalah asam benzoat. Asam benzoat lebih banyak digunakan dalam bentuk garamnya karena kelarutannya lebih baik daripada bentuk asamnya. Bentuk garam dari asam benzoat yang banyak digunakan adalah natrium benzoat. Benzoat dan turunannya dapat menghancurkan sel-sel mikroba terutama kapang. Natrium benzoat bekerja efektif pada $\mathrm{pH}$ 2,5-4 sehingga banyak digunakan pada makanan atau minuman yang bersifat asam (Winarno, 1980).

Struktur kimia asam benzoat seperti terlihat pada Gambar 1 .

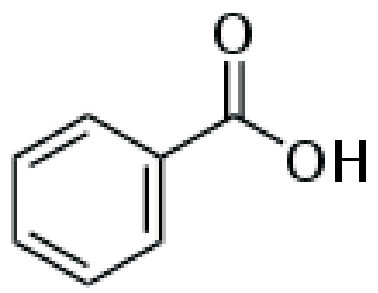

Gambar 1. Struktur kimia asam benzoat (Anonim, 1995) 
Sifat-sifat asam benzoat adalah sebagai berikut (Anonim, 1995) : Bobot molekul 122,12, mengandung tidak kurang dari $99,5 \%$ dan tidak lebih dari $100,5 \% \quad \mathrm{C}_{7} \mathrm{H}_{6} \mathrm{O}_{2}$ dihitung terhadap zat anhidrat, pemerian : hablur berbentuk jarum atau sisik, putih, sedikit berbau, biasanya bau benzaldehid atau benzoin. Agak mudah menguap pada suhu hangat, mudah menguap dalam uap air, kelarutan : sukar larut dalam air, mudah larut dalam etanol, dalam kloroform, dan dalam eter.

Asam benzoat merupakan salah satu pengawet yang diizinkan oleh Departemen Kesehatan untuk digunakan pada makanan. Menurut Permenkes RI No.722/Menkes/Per/IX/88, batas penggunaan asam benzoat pada minuman ringan dan kecap adalah $600 \mathrm{mg} / \mathrm{kg}$, sedangkan pada sari buah, saus, jelly, manisan dan agar adalah $1000 \mathrm{mg} / \mathrm{kg}$ (Anonim, 1988).

Penelitian mengenai efek toksik asam benzoat telah banyak dilakukan. Penelitian yang dilakukan oleh Wiley dan Bigelow (1908) menunjukkan bahwa pemberian $1000,1500,2000,2500$ $\mathrm{mg} /$ hari asam benzoat masing-masing selama 5 hari pada manusia menyebabkan terjadinya perasaan tidak nyaman dan malaise (mual, sakit kepala, kelemahan, rasa terbakar di perut, dan iritasi oesophagus). Hayun dkk (2004) menyatakan bahwa minuman ringan berkarbonasi mengandung asam benzoat. Kandungan asam benzoat dalam minuman ringan berkarbonasi masih di bawah batasan maksimal penggunaan asam benzoat yang ditetapkan. Pada penderita asma dan orang yang menderita urticaria sangat sensitif terhadap asam benzoat, jika dikonsumsi dalam jumlah besar akan mengiritasi lambung (Cahyadi, 2009). Penelitian ini bertujuan untuk mengetahui kadar asam benzoat dalam beberapa minuman ringan dan untuk mengetahui apakah penggunaan asam benzoat dalam minuman ringan sesuai dengan Permenkes RI No.722/Menkes/Per/IX/88 tentang bahan tambahan pangan.

\section{METODE PENELITIAN}

\section{Alat}

Alat yang digunakan pada penelitian ini adalah neraca analitik, alat-alat gelas (Pyrex) dengan berbagai ukuran, rotary evaporator (Buchi Rotavapor), kompor dan penangas air, cawan porselin, seperangkat alat spektrofotometer (PharmaSpec UV1700 Shimadzu).

\section{Bahan}

Bahan yang digunakan dalam penelitian ini adalah sampel minuman ringan, $\mathrm{FeCl}_{3}$ p.a (E. Merck), aquadest (Brataco), $\mathrm{NaCl}$ p.a (E. Merck), $\mathrm{NaOH}$ p.a (E. Merck), $\mathrm{HCl}$ p.a (E. Merck), kloroform p.a (E. Merck), etanol p.a (E. Merck), $\mathrm{NH}_{3}$ p.a (E. Merck), indikator pH (E. Merck), dan kertas saring.

\section{Jalannya Penelitian}

Sebanyak 5 merk sampel minuman ringan diambil di pasaran. Sampel untuk satu merk minuman diambil dari batch yang sama.

Masing-masing sampel diambil 40 $\mathrm{g}$ dan ditambahkan $3 \mathrm{~g} \mathrm{NaCl}$, kemudian dimasukkan ke dalam labu takar $100 \mathrm{ml}$. Selanjutnya ke dalam labu takar tersebut 
ditambahkan $40 \mathrm{ml}$ larutan $\mathrm{NaCl}$ jenuh dan $\mathrm{NaOH} 10 \%$ hingga diperoleh larutan yang bersifat alkalis $(\mathrm{pH} \pm 10)$. Larutan tersebut diencerkan dengan larutan $\mathrm{NaCl}$ jenuh sampai tanda batas dan dibiarkan selama 2 jam. Larutan tersebut dikocok setiap 30 menit dan selanjutnya disaring dengan kertas saring. Filtrat yang diperoleh kemudian diekstraksi.

Filtrat yang diperoleh dimasukkan ke dalam corong pisah, kemudian ditambah $\mathrm{HCl} \mathrm{5 \%} \mathrm{hingga} \mathrm{larutan} \mathrm{bersifat}$ netral. Setelah keadaan netral tercapai, ditambah 5,0 $\mathrm{ml} \mathrm{HCl}$. Selanjutnya diekstraksi dengan pelarut kloroform dengan volume berturut-turut 70, 50, 40, dan $30 \mathrm{ml}$. Lapisan kloroform ditampung dan diuapkan dengan rotary evaporator pada suhu $500 \mathrm{C}$ hingga volume $\pm 5 \mathrm{ml}$, diuapkan di atas waterboth dalam almari asam hingga kering. Ekstrak kering dilarutkan dengan etanol sampai 10,0 ml (Siaka, 2009).

\section{Analisis Data}

Analisis data meliputi uji kualitatif dilakukan dengan 2 cara, yaitu uji tabung dengan pereaksi $\mathrm{FeCl}_{3} 0,5 \%$ dan dengan membandingkan profil spektra sampel dengan profil spektra standar asam benzoat (Siaka, 2009). Uji kuantitatif diawali dengan pembuatan larutan induk asam benzoat $1,0 \mathrm{mg} / \mathrm{ml}$, penentuan panjang gelombang serapan maksimum, dan penentuan kadar asam benzoat di dalam sampel. Hasil perhitungan kadar dilanjutkan dengan analisis statistik.

\section{HASIL DAN PEMBAHASAN}

\section{Uji Kualitatif}

Uji kualitatif dilakukan untuk mengetahui ada tidaknya asam benzoat pada minuman tersebut. Uji kualitatif dilakukan dengan dua cara, yaitu uji dengan pereaksi $\mathrm{FeCl}_{3}$ dan dengan membandingkan antara spektra hasil ekstraksi sampel dengan spektra larutan standar asam benzoat.

Hasil analisis uji kualitatif dengan pereaksi $\mathrm{FeCl}_{3}$ seperti terlihat pada Gambar 2.

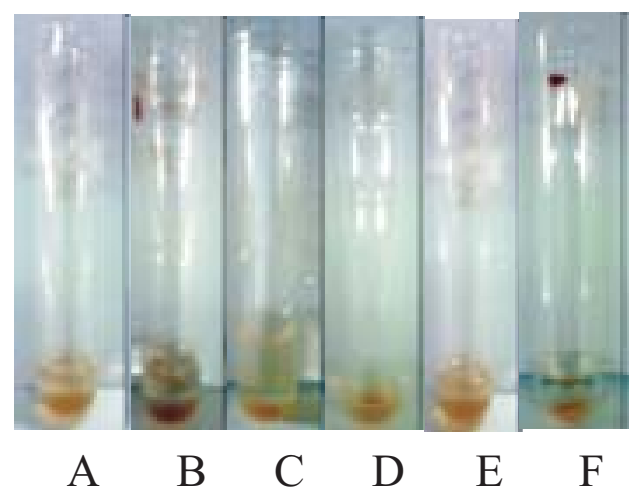

Gambar 2. Hasil Uji Kualitatif Asam Benzoat Standar dan Sampel

Keterangan :

$\mathrm{A}=$ Standar asam benzoat

$\mathrm{B}=$ Sampel Merk A

$\mathrm{C}=$ Sampel Merk B

$\mathrm{D}=$ Sampel Merk C

$\mathrm{E}=$ Sampel Merk D

$\mathrm{F}=$ Sampel Merk E

Ringkasan hasil analisis uji kualitatif dengan pereaksi $\mathrm{FeCl}_{3}$ tersebut tertulis dalam Tabel I. 
Tabel I. Hasil Analisis Uji Kualitatif Asam Benzoat

\begin{tabular}{|c|c|c|}
\hline Sampel & Hasil Uji & Ket \\
\hline A & End. jingga kekuningan & + \\
\hline B & End. jingga kekuningan & + \\
\hline C & End. jingga kekuningan & + \\
\hline D & End. jingga kekuningan & + \\
\hline E & End. jingga kekuningan & + \\
\hline Standar Asam Benzoat & End Jingga kekuningan & \\
\hline
\end{tabular}

Keterangan : $+=$ mengandung asam benzoat

Gambar 2 dan data pada Tabel I menunjukkan bahwa semua sampel minuman memberikan uji positif. Uji positif ditunjukkan dengan terbentuknya endapan yang berwarna jingga kekuningan setelah direaksikan dengan pereaksi $\mathrm{FeCl}_{3} \quad 0,5 \%$. Hal ini berarti bahwa semua sampel minuman mengandung bahan pengawet asam benzoat.

Endapan yang terbentuk tersebut adalah Besi(III)benzoat. Reaksi yang terjadi sebagai berikut :

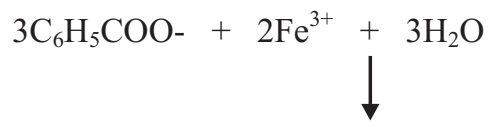

$\left(\mathrm{C}_{6} \mathrm{H}_{5} \mathrm{COO}\right)_{3} \mathrm{Fe} . \mathrm{Fe}(\mathrm{OH})_{3}+3 \mathrm{H}^{+}$(Vogel, 1985)

\section{Uji kualitatif juga dilakukan} dengan membandingkan antara spektra hasil ekstraksi sampel dengan spektrogram sinar UV larutan standar asam benzoat. Perbandingan bentuk spektra senyawa asam benzoat standar dan sampel seperti terlihat pada Gambar 3.

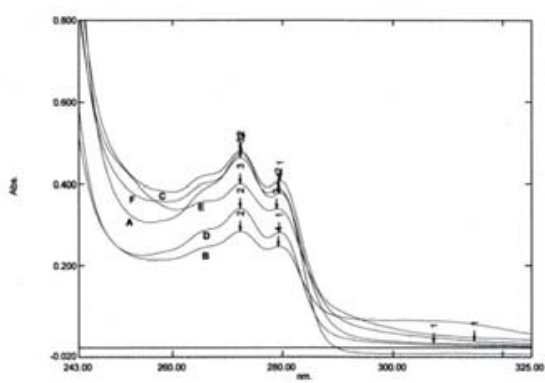

Gambar 3. Perbandingan Bentuk Spektrogram Sinar UV Asam Benzoat Standar dan Sampel

Keterangan :

$\mathrm{A}=$ Standar asam benzoat

$\mathrm{B}=$ Sampel Merk A

$\mathrm{C}=$ Sampel Merk B

$\mathrm{D}=$ Sampel Merk C

$\mathrm{E}=$ Sampel Merk D

$\mathrm{F}=$ Sampel Merk E

Dari Gambar 3 dapat dilihat bahwa kelima spektrogram sampel mempunyai profil yang sama dengan spektrogram larutan standar asam benzoat. Hal ini menunjukkan bahwa 
kelima sampel yang diambil mengandung asam benzoat.

\section{Uji Kuantitatif}

Hasil panjang gelombang serapan maksimum asam benzoat adalah pada $272,4 \mathrm{~nm}$. Pengukuran pada panjang gelombang serapan maksimum, bertujuan untuk mendapatkan serapan yang optimal.

Data hubungan antara konsentrasi standar dengan absorbansi dapat dilihat pada Tabel II dan pada Gambar 4.

Kurva baku yang diperoleh seperti terlihat pada Gambar 4.

Tabel II. Data Serapan Kurva Baku

\begin{tabular}{|c|c|c|}
\hline No & $\begin{array}{c}\text { Konsentrasi } \\
(\mathbf{m g} / \mathbf{m l})\end{array}$ & Absorbansi \\
\hline 1 & 0,04 & 0,242 \\
\hline 2 & 0,06 & 0,377 \\
\hline 3 & 0,08 & 0,496 \\
\hline 4 & 0,10 & 0,635 \\
\hline 5 & 0,12 & 0,766 \\
\hline
\end{tabular}

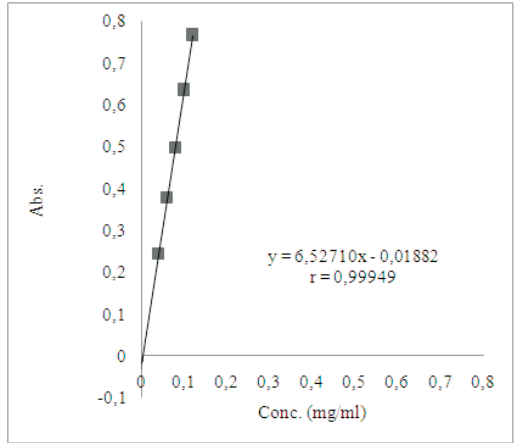

Gambar 4. Kurva Baku antara Konsentrasi Standar Asam Benzoat dan Serapan

Persamaan kurva baku yang diperoleh adalah $\mathrm{Y}=6,52710 \mathrm{x}-0,01882$ dengan nilai $r$ sebesar 0,99949 . Nilai $r$ tabel dengan $\mathrm{n}=5$ dan taraf kepercayaan $95 \%$ adalah 0,878 . Nilai $r$ hitung $>r$ tabel menunjukkan bahwa ada hubungan yang signifikan antara kadar larutan baku asam benzoat dengan serapan sehingga persamaan kurva baku tersebut dapat digunakan untuk menghitung kadar asam benzoat dalam sampel. Hasil perhitungan kadar asam benzoat dari lima merk minuman ringan disajikan pada Tabel III.

Tabel III. Kadar Asam Benzoat dalam Sampel

\begin{tabular}{|c|c|c|c|}
\hline Sampel & $\begin{array}{c}\overline{\mathbf{X}} \pm \mathbf{L E} \\
\mathbf{( m g / s a j i )}\end{array}$ & $\begin{array}{c}\overline{\mathbf{X}} \pm \mathbf{L E} \\
(\mathbf{m g} / \mathbf{k g} \text { bahan })\end{array}$ & $\mathbf{C V}$ (\%) \\
\hline $\mathrm{A}$ & $45,23 \pm 2,20$ & $227,73 \pm 11,07$ & $7,26 \%$ \\
\hline $\mathrm{B}$ & $29,59 \pm 1,05$ & $182,38 \pm 6,50$ & $3,74 \%$ \\
\hline $\mathrm{C}$ & $43,45 \pm 1,56$ & $259,53 \pm 8,90$ & $3,60 \%$ \\
\hline $\mathrm{D}$ & $75,32 \pm 3,40$ & $325,01 \pm 14,66$ & $5,48 \%$ \\
\hline $\mathrm{E}$ & $47,78 \pm 1,58$ & $357,33 \pm 14,38$ & $4,02 \%$ \\
\hline
\end{tabular}


Data pada Tabel III menunjukkan bahwa kandungan asam benzoat dari semua sampel yang diteliti memenuhi Permenkes RI No.722/Menkes/Per/ IX/88 (Anonim, 1988) tentang bahan tambahan pangan, batas penggunaan asam benzoat pada minuman ringan dan kecap adalah $600 \mathrm{mg} / \mathrm{kg}$. Kandungan asam benzoat dalam semua sampel yang diteliti di bawah batasan maksimal penggunaannya, yaitu di bawah 600 $\mathrm{mg} / \mathrm{kg}$ bahan.

Batas penggunaan bahan tambahan pangan dibatasi dengan nilai ADI (Acceptable Daily Intake), yaitu batasan maksimal penggunaannya dalam sehari. Nilai ADI bahan pengawet asam benzoat adalah sebesar $5 \mathrm{mg} / \mathrm{kg}$ BB. Berat badan penduduk Indonesia rata-rata $60 \mathrm{~kg}$. Jadi batasan maksimal konsumsi asam benzoat sebesar 300 $\mathrm{mg} /$ hari. Jumlah asam benzoat dalam semua sampel yang diteliti masih di bawah batasan maksimal kosumsi asam benzoat tiap harinya. Batas aman konsumsi Merk A maksimal 6 kemasan/hari, Merk B maksimal 10 kemasan/hari, Merk C maksimal 6 kemasan/hari, Merk D maksimal 3 kemasan/hari, dan Merk E maksimal 6 kemasan/hari.

\section{Analisis Statistik}

Pada penelitian ini digunakan taraf kepercayaan 95\%. Nilai á untuk taraf kepercayaan $95 \%$ adalah 0,05 . Dari hasil uji Kolmogorov-Smirnov diperoleh nilai signifikansi 0,838 . Nilai signifikansi $>0,05$, Ho diterima. Jadi data terdistribusi normal. Dari hasil uji Levene diperoleh nilai signifikansi 0,606 . Nilai signifikansi $>0,05$, Ho diterima. Jadi varian data homogen. Dari hasil uji Anova diperoleh nilai signifikansi 0,000 . Nilai signifikansi $<0,05$, Ha diterima. Jadi ada perbedaan kadar asam benzoat dari masing-masing sampel. Dari hasil uji LSD (Least Significant Difference) diperoleh nilai signifikansi 0,000 dan 0,001 . Nilai signifikansi $<0,05$, Ha diterima. Jadi kadar asam benzoat dalam tiap sampel berbeda bermakna.

\section{KESIMPULAN}

1. Minuman ringan Merk A, B, C, D, dan $\mathrm{E}$ mengandung pengawet sintetik asam benzoat.

2. Kadar asam benzoat dalam minuman ringan Merk A $(227,73 \pm 11,07)$ $\mathrm{mg} / \mathrm{kg}$ bahan; $\mathrm{CV}=7,26 \%$, Merk B $(182,38 \pm 6,50) \mathrm{mg} / \mathrm{kg}$ bahan; $\mathrm{CV}=$ $3,74 \%$, Merk C $(259,52 \pm 8,90)$ $\mathrm{mg} / \mathrm{kg}$ bahan; $\mathrm{CV}=3,60 \%$, Merk D $(325,01 \pm 14,66) \quad \mathrm{mg} / \mathrm{kg}$ bahan; $\mathrm{CV}=5,48 \%$, Merk $\mathrm{E}(357,33 \pm 11,83)$ $\mathrm{mg} / \mathrm{kg}$ bahan; $\mathrm{CV}=4,02 \%$.

3. Penggunaan asam benzoat dalam minuman ringan sesuai dengan Permenkes RI No.722/Menkes/Per/ IX/88, tidak melebihi batasan maksimal yang ditentukan yaitu sebesar $600 \mathrm{mg} / \mathrm{kg}$ bahan.

4. Minuman ringan dengan merk yang berbeda mengandung asam benzoat dengan kadar yang berbeda.

\section{DAFTAR PUSTAKA}

Anonim, 1988, Peraturan Menteri Kesehatan RI. Nomor: 722/MenKes/Per/IX/88 Tentang Bahan Tambahan Makanan, Departemen Kesehatan RI, Jakarta. 
Anonim, 1995, Farmakope Indonesia, Ed. IV,47-48,548, Departemen Kesehatan RI, Jakarta.

Anonim, 2000, Benzoic Acid And Sodium Benzoate, World Health Organization, Geneva, http://www.who.int, diakses pada tanggal 8 Mei 2010.

Cahyadi, Wisnu, 2009, Analisis dan Aspek Kesehatan Bahan Tambahan Pangan, 5-60, Bumi Aksara, Jakarta.

Hayun, Yahdiana Harahap, dan Citra Nur Aziza, 2004, Penetapan Kadar Sakarin, Asam Benzoat, Asam Sorbat, Kofeina, Dan Aspartam di Dalam Beberapa Minuman Ringan Bersoda Secara Kromatografi Cair Kinerja Tinggi, Majalah Ilmu Kefarmasian, Vol. I, No.3, Desember 2004, 148 159, http://jurnal.farmasi.ui.ac.id, diakses pada tanggal 28 April 2010.
Jacobson, Michael. 2000. How soft drinks are harming Americans' health, http://www.cspinet.org, diakses pada tanggal 21 Oktober 2010.

Siaka, 2009, Analisis Bahan Pengawet Benzoat Pada Saos Tomat yang Beredar di Wilayah Kota Denpasar, Jurnal Kimia 3 (2), Juli 2009 $87-92$, http://jurnal.pdii.lipi.go.id, diakses pada tanggal 8 Maret 2010.

Vogel, (Eds)., 1985, Buku Teks Analisis Anorganik Kualitatif Makro dan Semimikro, Edisi Kelima, diterjemahkan oleh Setiono dan Hadyana Pudjaatmaka, 402-403, PT. Kalman Media Pustaka, Jakarta.

Winarno, Srikandi F, Dedi F, 1980, Pengantar Teknologi Pangan, PT Gramedia, Jakarta. 